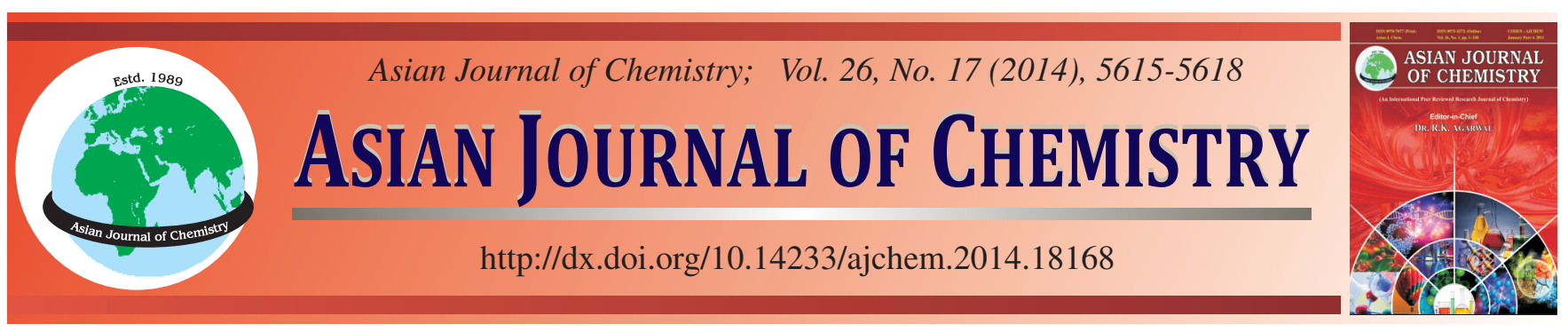

\title{
Acrylamide/2-Acrylamido-2-methylpropanesulfonic acid/1-Vinyl-2-pyrrolidinone Terpolymeric Microspheres by Orthogonal Experiments $\dagger$
}

\author{
Qian Zhao , Meiqin Lin, Shuangmin Dang and Zhao Hua
}

Research Institute of Enhanced Oil Recovery, China University of Petroleum, Beijing, P.R. China

*Corresponding author: Tel: +86 10 89733437; E-mail: mqlin@cup.edu.cn

\begin{abstract}
Polyacrylamide microspheres were soft, flexible, deformable, thermostability and halotolerant micro-gel particles that could be used as deep profile control agent in oil fields with the ultimate purpose of improving oil recovery. In this study, a series of terpolymeric microspheres were prepared through inverse suspension polymerization using the monomers of acrylamide (AM), 2-acrylamido-2-methylpropanesulfonic acid (AMPS) and 1-vinyl-2-pyrrolidinone (NVP). By orthogonal experiments, the formulation optimized can be selected. The shape and size were investigated by electron microscope (EMS), scanning electron microscope (SEM) and light diffraction particle size analyzer and the thermal stability was examined by high-temperature water solution. The experimental results showed that the terpolymeric microspheres has good monodispersity. Under suitable reaction conditions, the particle size and swelling properties of microspheres were influenced significantly by the monomer ratio.
\end{abstract}

Keywords: Microspheres, Terpolymeric, Orthogonal experiments.

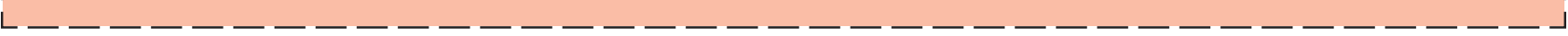

\section{INTRODUCTION}

Polyacrylamide has a long history in oil field application to guarantee stable oil production. The polyacrylamide microspheres can easily migrate into the interior layers to accomplish indepth profile control for the size, water absorbing selectivity, brine tolerance, good dispersion in water ${ }^{1,2}$.

A disadvantage of polyacrylamide is the sensitivity of the amide group to the hydrolysis reaction ${ }^{3}$. At $100{ }^{\circ} \mathrm{C}$ almost all the amide groups in a polymer are hydrolyzed in a few days, under some conditions degradation of the polymeric chain may also occur. It leads to a reduction in the molecular weight of polymer, which might affect even further the properties of the polymeric solutions ${ }^{4}$.

To improve the thermal stability many different monomers have been prepared. Such as the sodium-2-acrylamido-2methylpropane sulfonate (AMPS) and $\mathrm{N}$-vinyl pyrrolidone (NVP). 2-Acrylamido-2-methylpropanesulfonic acid is a secondary amide and it is known that these are less susceptible to hydrolysis than primary amides and the alkyl chain is a gem-dimethyl group, which can impart further protection due to steric hindrance. It has been observed that the solutions of homopolymer of NVP did not suffer significant changes in properties after aging at $120{ }^{\circ} \mathrm{C}$ for 3 month. However, PVP does not have good viscosifying property. The hydrolysis limit of the amide groups decreased as the mole fraction of NVP in the polymer increased ${ }^{5-7}$.

In this paper, a series of terpolymeric microspheres were prepared through inverse suspension polymerization using the monomers of acrylamide (AM), 2-acrylamido-2-methylpropanesulfonic acid (AMPS) and 1-vinyl-2-pyrrolidinone. By orthogonal experiments. The formulation optimized are selected.

\section{EXPERIMENTAL}

Acrylamide (AM): AR, Beijing Modern Oriental Chem. Co. Ltd. (China); 2-acrylamide-2-methylpro panesulfonic acid (AMPS): Industrial, Weifang Quanxin Chem. Co. Ltd. (China): N-Vinyl-2-pyrrolidone(NVP): AR, TCI-Tokyo Chemical Industry Co., Ltd. (Japan); N-N'-methylene-bis acrylamide (NMBA), potassium persulfate (KPS): CP, Tianjin Guangfu fine Chemical Research Institute(China); OP emulsifier: AR, Tianjin Fucheng Chem. Co. (China); cyclohexane, dehydration of sorbitol fatty acid esters (Span80), ethanol: AR, Beijing Yili Fine chem. Co. Ltd. (China).

General procedure: A certain amount of Span80 was added into cyclohexane stirred until clear into oil phase and a 
certain amount of AM, AMPS, NVP, NMBA and KPS were dissolved in water into aqueous phase. Oil phase was poured into a $250 \mathrm{~mL}$ three-necked flask placed in water bath, being stirred by a IKA EUROSTAR40 overhead stirrer (German) with a certain stirring speed, meantime, the aqueous phase was added drop wise under constant pressure. After few hours, the product was washed with ethanol subsequently and then dried in a $50{ }^{\circ} \mathrm{C}$ oven for $24 \mathrm{~h}$. Slightly yellow copolymer microspheres were obtained finally, with a nearly $100 \%$ yield. We determined the reaction temperature is 66 to $70{ }^{\circ} \mathrm{C}$ through a number of preliminary experience and the amount of cyclohexane was $80 \mathrm{~g}$. The influences of monomer ratio (AM:AMPS: NVP), the amount of the crosslinker, emulsifier and deionized water to swelling and heat resistance properties of copolymer microspheres were studied. Taking the original particle size, swelling and heat resistance properties as indexes, we did five factors and four levels orthogonal experiment and made a $\mathrm{L}_{16}\left(4^{5}\right)$ orthogonal table. The factor-level table by inverse suspension polymerization was shown in Table-1.

\begin{tabular}{cccccc}
\multicolumn{7}{c}{ TABLE-1 } \\
FACTOR-LEVEL TABLE BY INVERSE \\
SUSPENSION POLYMERIZATION
\end{tabular}

Detection method: A small amount of microsphere powder was added into the Macrotrac S3500 laser particle size analyzer (USA), using ethanol as circulating liquid in the system. Original particle size of the microspheres was measured and the average particle diameters were compared among different samples.

$0.2 \mathrm{~g}$ microspheres placed in $200 \mathrm{~mL}$ water at room temperature $\left(30^{\circ} \mathrm{C}\right)$ swelled for $48 \mathrm{~h}$. A certain amount of this solution was added into the laser particle size analyzer to measure the particle size, using water as circulating liquid in the system. The volume of swelling multiples $\mathrm{R}^{3} / \mathrm{R}_{0}^{3}$ can be calculated through comparing the original particle size $\mathrm{R}_{0}$ and swelled particle size R.

$0.1 \mathrm{~g}$ microspheres were added into a sealed glass bottle containing $20 \mathrm{~mL}$ water, then the bottle was placed in an oven at $120^{\circ} \mathrm{C}$, being observed and photographed every $24 \mathrm{~h}$. The microspheres solution could be observed by BX-41 optical electron microscope (Japan) as well. From the day the bottle being placed in the oven to the day when microspheres was almost degraded, we could calculate the days of heat resistance.

The morphology of the microsphere powder polymerized by reverse emulsion polymerization was observed and photographed by FEI SIRION 200 field emission scanning electron microscope (SEM). Comparing the morphology of microspheres prepared in 9 orthogonal experiments, we would grade them according to the ball ability and monodispersity.

\section{RESULTS AND DISCUSSION}

The results of products in $\mathrm{L}_{16}\left(4^{5}\right)$ orthogonal experiments were shown in Table-2. In Table-3, monomer ratio had the greatest influence on original particle size of terpolymer microspheres. From 7:0:3 to 7:3:0, the particle size decreased. Because the relative molecular mass of AMPS was 206 and NVP's was 111, which was almost half of 206. As the weight of AMPS increased and NVP's decreased, the mole number of monomers in water-in-oil droplets decreased, which made original particle size of terpolymer microspheres decreased. That is, under the same other reaction conditions and the total

\begin{tabular}{|c|c|c|c|c|}
\hline \multicolumn{5}{|c|}{$\begin{array}{c}\text { TABLE-2 } \\
\text { RESULTS OF ORTHOGONAL EXPERIMENTS } \\
\text { BY INVERSE SUSPENSION POLYMERIZATION }\end{array}$} \\
\hline \multirow[b]{2}{*}{ No. } & $\mathrm{A}$ & B & $\mathrm{C}$ & $\mathrm{D}$ \\
\hline & $\begin{array}{c}\text { Monomer } \\
\text { ratio }\end{array}$ & $\begin{array}{c}\text { Crosslinker } \\
(\mathrm{g})\end{array}$ & Initiator (g) & $\begin{array}{c}\text { Emulsifier } \\
(\mathrm{g})\end{array}$ \\
\hline 1 & 1 & 1 & 1 & 1 \\
\hline 2 & 1 & 2 & 2 & 2 \\
\hline 3 & 1 & 3 & 3 & 3 \\
\hline 4 & 1 & 4 & 4 & 4 \\
\hline 5 & 2 & 1 & 2 & 3 \\
\hline 6 & 2 & 2 & 1 & 4 \\
\hline 7 & 2 & 3 & 4 & 1 \\
\hline 8 & 2 & 4 & 3 & 2 \\
\hline 9 & 3 & 1 & 3 & 4 \\
\hline 10 & 3 & 2 & 4 & 3 \\
\hline 11 & 3 & 3 & 1 & 2 \\
\hline 12 & 3 & 4 & 2 & 1 \\
\hline 13 & 4 & 1 & 4 & 2 \\
\hline 14 & 4 & 2 & 3 & 1 \\
\hline 15 & 4 & 3 & 2 & 4 \\
\hline 16 & 4 & 4 & 1 & 3 \\
\hline \multirow[b]{2}{*}{ No. } & \multicolumn{4}{|c|}{ Results } \\
\hline & $\begin{array}{l}\text { Original } \\
\text { size }(\mu \mathrm{m})\end{array}$ & $\begin{array}{l}\text { Swelled size } \\
\qquad(\mu \mathrm{m})\end{array}$ & $\begin{array}{l}\text { Days of } \\
\text { heat } \\
\text { resistance }\end{array}$ & $\begin{array}{l}\text { Volume } \\
\text { multiples }\end{array}$ \\
\hline 1 & 103.90 & 191.7 & 4 & 6.28 \\
\hline 2 & 74.66 & 121.9 & 5 & 4.35 \\
\hline 3 & 79.45 & 129.6 & 6 & 4.34 \\
\hline 4 & 64.82 & 105.7 & 7 & 4.35 \\
\hline 5 & 60.04 & 127.8 & 11 & 6.28 \\
\hline 6 & 50.71 & 107.4 & 11 & 9.51 \\
\hline 7 & 57.67 & 119.4 & 9 & 8.87 \\
\hline 8 & 73.39 & 134.2 & 11 & 6.11 \\
\hline 9 & 50.53 & 126.0 & 9 & 15.50 \\
\hline 10 & 50.83 & 148.4 & 9 & 24.90 \\
\hline 11 & 43.78 & 125.1 & 10 & 23.20 \\
\hline 12 & 48.51 & 128.6 & 9 & 18.60 \\
\hline 13 & 54.41 & 325.7 & 3 & 214.50 \\
\hline 14 & 53.90 & 286.1 & 4 & 145.40 \\
\hline 15 & 40.92 & 222.9 & 5 & 161.60 \\
\hline 16 & 41.60 & 138.4 & 5 & 36.80 \\
\hline
\end{tabular}

\begin{tabular}{ccccccc}
\multicolumn{7}{c}{ TABLE-3 } \\
\multicolumn{7}{c}{ DATA ANALYSIS OF ORTHOGONAL } \\
EXPERIMENTS-ORIGINAL PARTICLE SIZE \\
\hline Index & & $\mathrm{A}$ & $\mathrm{B}$ & $\mathrm{C}$ & $\mathrm{D}$ & $\mathrm{E}$ \\
\hline \multirow{2}{*}{ Original } & $\mathrm{k} 1$ & 80.71 & 67.22 & 60.00 & 66.00 & 67.26 \\
particle & $\mathrm{k} 3$ & 60.45 & 57.53 & 56.03 & 61.56 & 56.12 \\
size & $\mathrm{k} 4$ & 47.41 & 55.46 & 64.32 & 57.98 & 58.27 \\
& $\mathrm{R}$ & 33.00 & 10.14 & 8.29 & 14.25 & 11.62 \\
\hline
\end{tabular}


amount of monomers and AM unchanged, when the amount of AMPS increased and NVP's decreased, the particle size would reduce, otherwise, it would increase. The particle size would reduce obviously with the increased amount of emulsifier, the more the amount of emulsifier, the better the emulsification effect, the smaller the oil in water droplets, resulting in less monomers, initiator and crosslinker, which made original particle size of terpolymer microspheres decreased. When the amount of crosslinker was the least, the particle size increased obviously. It showed that the internal structure was relatively looser with the less amount of crosslinker, leading to the bigger particle size. When the volume of water was $30 \mathrm{~mL}$, the particle size increased obviously. It may be explained as follows: when the amount of water became less, the oil in water droplets became bigger relatively, resulting in more monomers in droplets and bigger particle size. Finally, the influence of the amount of initiator on original particle size was the least. Original particle size didn't change obviously with the change of initiator's amount.

The EMS photographs of the terpolymeric microspheres before and after swelling in water solution were shown in Fig. 1, it can be seen that the original size of microspheres is less than $90 \mu \mathrm{m}$, however, the size of swelling for $24 \mathrm{~h}$ is 100 to $300 \mu \mathrm{m}$.

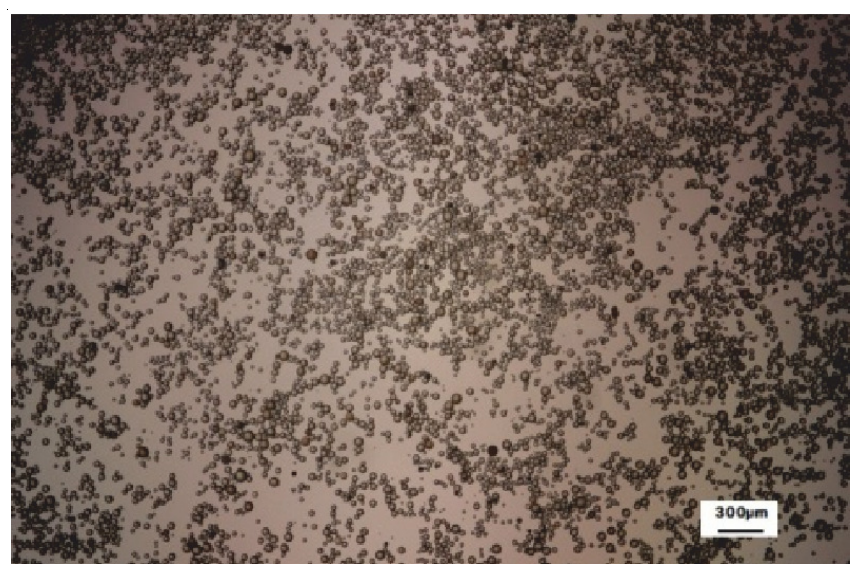

(a) Before swelling

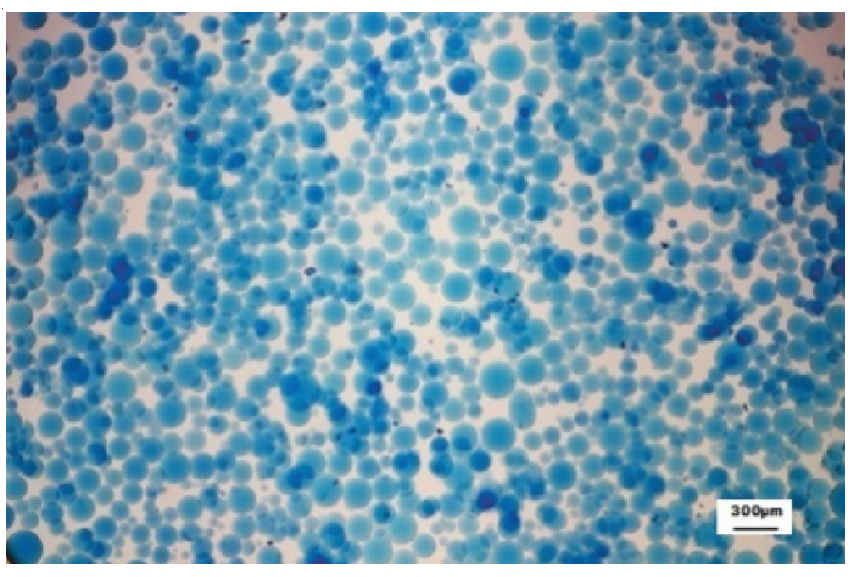

(b) After swelling

Fig. 1. EMS photographs images of terpolymer microspheres before and after swelling
As shown in Tables 4 and 5, monomer ratio had the biggest influence on swelling property of terpolymer microspheres. When the monomer ratio was 7:3:0, the swelled volume was $139.58 \mu \mathrm{m}^{3}$. Whereas, it turned only $4.83 \mu \mathrm{m}^{3}$ while the monomer ratio was 7:0:3. It showed that the swelled volume increased obviously with increased AMPS and decreased NVP. Because the sulfonic acid group $\left(-\mathrm{SO}_{3} \mathrm{H}\right)$ in AMPS ionized into strong electro-negative groups $\left(-\mathrm{SO}_{3}-\right)$ in water, which made that the internal spatial structure of microspheres extended and stretched fully, the process of swelling was shown in Fig. 2.

\begin{tabular}{|c|c|c|c|c|c|c|}
\hline \multicolumn{7}{|c|}{$\begin{array}{c}\text { TABLE-4 } \\
\text { DATA ANALYSIS OF ORTHOGONAL EXPERIMENTS- } \\
\text { SWELLING PROPERTY }\end{array}$} \\
\hline Index & & A & B & $\mathrm{C}$ & D & $\mathrm{E}$ \\
\hline \multirow{5}{*}{$\begin{array}{l}\text { Swelling } \\
\text { multiples }\end{array}$} & $\mathrm{k} 1$ & 4.83 & 60.64 & 18.95 & 44.80 & 49.72 \\
\hline & $\mathrm{k} 2$ & 7.82 & 46.04 & 48.36 & 62.05 & 16.38 \\
\hline & $\mathrm{k} 3$ & 20.56 & 49.51 & 42.84 & 18.08 & 61.74 \\
\hline & $\mathrm{k} 4$ & 139.58 & 16.47 & 63.15 & 47.74 & 44.82 \\
\hline & $\mathrm{R}$ & 134.75 & 44.17 & 44.20 & 43.97 & 45.36 \\
\hline
\end{tabular}

\begin{tabular}{|c|c|c|c|c|c|c|}
\hline \multicolumn{7}{|c|}{$\begin{array}{c}\text { TABLE-5 } \\
\text { DATA ANALYSIS OF ORTHOGONAL EXPERIMENTS- } \\
\text { THE DAYS OF HEAT RESISTANCE }\end{array}$} \\
\hline Index & & A & B & $\mathrm{C}$ & D & $\mathrm{E}$ \\
\hline \multirow{5}{*}{$\begin{array}{l}\text { Days of } \\
\text { heat } \\
\text { resistance }\end{array}$} & K1 & 5.50 & 6.75 & 7.50 & 6.50 & 7.25 \\
\hline & $\mathrm{K} 2$ & 10.05 & 7.25 & 7.50 & 6.75 & 7.00 \\
\hline & K3 & 9.25 & 7.50 & 7.50 & 7.75 & 7.00 \\
\hline & K4 & 4.25 & 8.00 & 8.00 & 8.00 & 8.00 \\
\hline & $\mathrm{R}$ & 5.80 & 1.25 & 0.50 & 1.50 & 1.00 \\
\hline
\end{tabular}

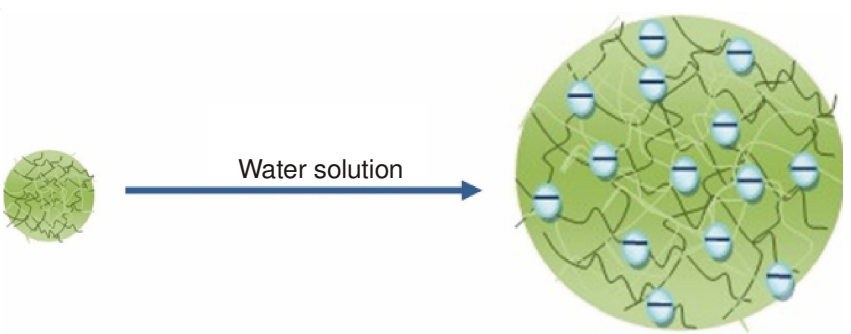

Fig. 2. Process of swelling

The volume swelling multiples of microspheres decreased roughly with increased crosslinker. This could be explained as. The internal structure of microspheres became denser with more crosslinker, which hindered the swelling of microspheres; volume swelling multiples of microspheres increased roughly with more initiator. In the initiation temperature, more initiator generated more active centers and faster initiation rate, resulting in reduced crosslinking density, so the internal structure was relatively loose; the change of the amount of emulsifier and water didn't have obvious influence on swelling property.

The formulation optimized can be selected from the data analysis (Table-6). The terpolymeric microspheres has outstanding thermal stability that can exist in $120{ }^{\circ} \mathrm{C}$ water solution for 19 days. The SEM photograph of terpolymeric microspheres with the formulation by inverse suspension polymerization was shown in Fig. 3, the size is $60-90 \mu \mathrm{m}$, the monodispersity is excellent. The monomer ratio has the greatest influence on original particle size, swelling property and thermal stability of terpolymer microspheres. By orthogonal 


\begin{tabular}{cccccc}
\hline \multicolumn{7}{c}{ TABLE-6 } \\
\hline $\begin{array}{c}\text { Monomer } \\
\text { ratio }\end{array}$ & $\begin{array}{c}\text { Crosslinker } \\
(\%)\end{array}$ & $\begin{array}{c}\text { Initiator } \\
(\%)\end{array}$ & $\begin{array}{c}\text { Emulsifier } \\
(\%)\end{array}$ & $\begin{array}{c}\text { Water } \\
(\mathrm{g})\end{array}$ & $\begin{array}{c}\text { Heat } \\
\text { resistance } \\
(\mathrm{d})\end{array}$ \\
\hline $7: 1.5: 1.5$ & 0.5 & 1.5 & 5 & 40 & 19 \\
\hline
\end{tabular}

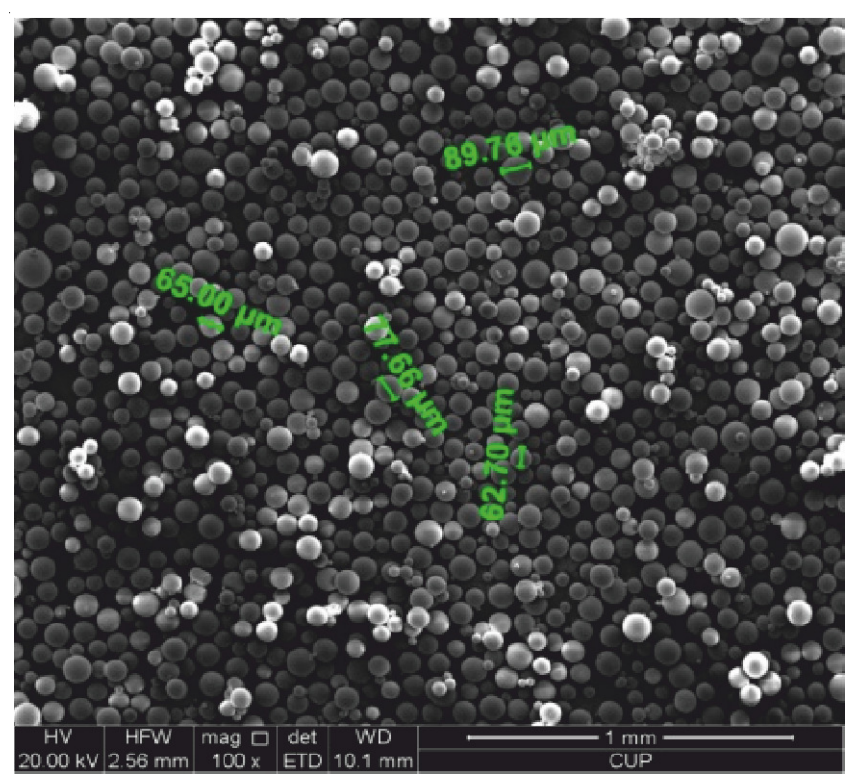

Fig. 3. SEM photograph of terpolymeric microspheres with formulation optimized experiments, the formulation optimized are selected. The monomer ratio (AM:AMPS:NVP) is 7:1.5:1.5, the crosslinker NMBA is $0.5 \%$, the KPS is $1.5 \%$, the water is $40 \mathrm{~g}$ and the terpolymeric microspheres has good monodispersity and outstanding thermal stability in high temperature water solution for 19 days.

\section{ACKNOWLEDGEMENTS}

The authors are thankful for support from Project supported by the National Natural Science Foundation of China and Research Institute of Enhanced Oil Recovery, China University of Petroleum, Beijing.

\section{REFERENCES}

1. H. Dakuang, Petroleum Explor. Develop., 37, 583 (2010).

2. J. Liang, H. Sun and R.S. Seright, SPE 24195 (1992).

3. T.P. Davis and M.B. Huglin, Polymer, 31, 513 (1990).

4. L. Puig, D.J.C. Sanchez and M. Villacampa, J. Colloid Interf. Sci., 235, 278 (2001).

5. G. Chauveteau, R. Tabary and M. Renard, SPE 89390, pp. 1-8 (2004).

6. H. Frampton, J.C. Morgan and S.K. Cheung, Development of a Novel Waterflood Conformance Control System, SPE 89391, pp. 1-9 (2004).

7. I.J. Fernández, PDVSA-Intevep, SPE International Symposium on Oilfield Chemistry, The Woodlands, Texas, 2-4 February (2005). 